\title{
Does Monetary Policy Have Significant Impact on Housing Prices? Evidence from Principal Component Analysis
}

\author{
Tian-Li LEI ${ }^{1, a}$, Gang WU ${ }^{2, b,}{ }^{*}$, Dong-Ping WEI ${ }^{3, c}$ \\ ${ }^{1}$ Department of Mathematics and Physics, Shenzhen Polytechnic, Shenzhen, China, 518005 \\ ${ }^{2}$ School of Construction and Environment, Shenzhen Polytechnic, Shenzhen, China, 518005 \\ ${ }^{3}$ Department of Mathematics and Physics, Shenzhen Polytechnic, Shenzhen, China, 518005 \\ att|@szpt.edu.cn, bszwug@163.com, cwdp@szpt.edu.cn \\ ${ }^{*}$ Corresponding author
}

Keywords: Monetary policy, Housing prices, Principal component analysis.

\begin{abstract}
We construct a housing price model based on supply and demand equilibrium, and use principal component analysis to avoid multicollinearity of independent variables. Empirical analysis of China's 35 big-to-medium sized cities average data shows that housing price expectation is the key factor for housing price increase. The impact elasticity of housing price expectation and GDP are 0.46 and 0.08 respectively, while the elasticity of mortgage loan and money supply are between 0.08 and 0.1 . It also shows that China's macro control policy is nearly invalid.
\end{abstract}

\section{Introduction}

The most commonly used monetary policy instruments are interest rate, credit and money supply. Most researchers find that housing prices are negatively related to interest rate change $[1,2,3,4,5,6]$. Bank loan has a direct impact on housing prices. Most domestic research find that a loose credit policy may cause housing price increase[7,8,9], While foreign research tends to believe that loose credit is not the main reason for housing price booming [10,11]. As China's money supply has a two digit increase for the past decade, so most Chinese research shows money supply has positive impact on housing prices $[12,13]$.

As there may exist co linearity between housing supply and bank loan, we use principal component analysis to avoid this problem. We use China's 35 big-to-medium sized cities' data spans 2000-2012 to find the key monetary policy to affect housing prices.

\section{Econometric Model}

For buyer $\mathrm{i}, \mathrm{B}_{\mathrm{i}}, \mathrm{L}_{\mathrm{i}}$ and $\mathrm{r}$ stands for mortgage loan, monthly payment and mortgage interest rate respectively; $t$ stands for loan periods. Then the bank loan is:

$$
\mathrm{B}_{\mathrm{i}}=\mathrm{L}_{\mathrm{i}} * \frac{(1+\mathrm{r})^{\mathrm{t}}-1}{\mathrm{r}(1+\mathrm{r})^{\mathrm{t}}}
$$

B is used to stands for the total loan in an area; L stands for the total monthly payment, then:

$$
B=\sum_{i} B_{i}=\sum_{i} L_{i} \cdot \frac{(1+r)^{t}-1}{r(1+r)^{t}}=\frac{(1+r)^{t}-1}{r(1+r)^{t}} \sum_{i} L_{i}=\frac{(1+r)^{t}-1}{r(1+r)^{t}} \cdot L
$$

Equation (2) can be modified as: 


$$
\mathrm{L}=\mathrm{B} \cdot \frac{\mathrm{r}(1+\mathrm{r})^{\mathrm{t}}}{(1+\mathrm{r})^{\mathrm{t}}-1}
$$

Suppose the housing demand elasticity of housing price $\mathrm{P}$, monthly payment $\mathrm{L}$, housing price expectation $\mathrm{E}$, wealth $\mathrm{Y}$ and money supply $\mathrm{M}$ is $-\alpha,-\beta, \gamma, \eta, \delta$ respectively, then housing demand can be expressed as:

$$
\mathrm{DQ}=\mathrm{c} \cdot \mathrm{P}^{-\alpha} \cdot \mathrm{L}^{-\beta} \cdot \mathrm{E}^{\gamma} \cdot \mathrm{Y}^{\eta} \cdot \mathrm{M}^{\delta}
$$

From theoretical analysis, we can suppose that,

$$
\frac{\partial \mathrm{DQ}}{\partial \mathrm{P}}<0, \frac{\partial \mathrm{DQ}}{\partial \mathrm{A}}<0, \frac{\partial \mathrm{DQ}}{\partial \mathrm{E}}>0, \frac{\partial \mathrm{DQ}}{\partial \mathrm{Y}}>0, \frac{\partial \mathrm{DQ}}{\partial \mathrm{M}}>0 \text {, which means: }
$$

$\alpha>0, \beta>0, \gamma>0, \eta>0, \delta>0$.

Substitute equation (3) into equation (4),

$$
\mathrm{DQ}=\mathrm{c} \cdot \mathrm{P}^{-\alpha} \cdot \mathrm{B}^{-\beta} \cdot\left(\frac{(1+\mathrm{r})^{\mathrm{t}}-1}{\mathrm{r}(1+\mathrm{r})^{\mathrm{t}}}\right)^{\beta} \cdot \mathrm{E}^{\gamma} \cdot \mathrm{Y}^{\eta} \cdot \mathrm{M}^{\delta}
$$

Suppose housing supply was mainly affected by housing price and interest rate, the elasticity of price and interest rate are $\mu$ and $-v$ respectively, then:

$$
\mathrm{SQ}=\mathrm{d} \cdot \mathrm{P}^{\mu} \cdot \mathrm{r}^{-\mathrm{v}}
$$

Among which, $\frac{\partial \mathrm{SQ}}{\partial \mathrm{P}}>0 ; \frac{\partial \mathrm{SQ}}{\partial \mathrm{r}}<0$. Which means: $\mu>0, v>0$.

When housing market is equilibrium, $\mathrm{DQ}=\mathrm{SQ}$, we can derive that:

$$
P=\left(\frac{c}{d}\right)^{\frac{1}{\alpha+\mu}} \cdot B^{-\frac{\beta}{\alpha+\mu}} \cdot\left(\frac{(1+r)^{t}-1}{r(1+r)^{t}}\right)^{\frac{\beta}{\alpha+\mu}} \cdot r^{\frac{v}{\alpha+\mu}} \cdot E^{\frac{\gamma}{\alpha+\mu}} \cdot Y^{\frac{\eta}{\alpha+\mu}} \cdot M^{\frac{\delta}{\alpha+\mu}}
$$

The Logarithmic form (use lower case to indicate) is:

$$
\mathrm{p}=\ln \left(\frac{\mathrm{c}}{\mathrm{d}}\right)-\frac{\beta}{\alpha+\mu} \cdot \mathrm{b}+\frac{\beta}{\alpha+\mu} \cdot \ln \left(\frac{(1+\mathrm{r})^{\mathrm{t}}-1}{\mathrm{r}(1+\mathrm{r})^{\mathrm{t}}}\right)+\frac{v}{\alpha+\mu} \cdot \ln \mathrm{r}+\frac{\gamma}{\alpha+\mu} \cdot \mathrm{e}+\frac{\eta}{\alpha+\mu} \cdot \mathrm{y}+\frac{\delta}{\alpha+\mu} \cdot \mathrm{m}
$$

Which can be simplified as,

$$
\mathrm{p}=\mathrm{c}_{1}-\mathrm{c}_{2} \cdot \mathrm{b}+\mathrm{c}_{2} \cdot \ln \left(\frac{(1+\mathrm{r})^{\mathrm{t}}-1}{\mathrm{r}(1+\mathrm{r})^{\mathrm{t}}}\right)+\mathrm{c}_{3} \cdot \ln \mathrm{r}+\mathrm{c}_{4} \cdot \mathrm{e}+\mathrm{c}_{5} \cdot \mathrm{y}+\mathrm{c}_{6} \cdot \mathrm{m}
$$

Among which: $\mathrm{c}_{1}=\ln \left(\frac{\mathrm{c}}{\mathrm{d}}\right), \mathrm{c}_{2}=\frac{\beta}{\alpha+\mu}, \mathrm{c}_{3}=\frac{v}{\alpha+\mu}, \mathrm{c}_{4}=\frac{\gamma}{\alpha+\mu}, \mathrm{c}_{5}=\frac{\eta}{\alpha+\mu}, \mathrm{c}_{6}=\frac{\delta}{\alpha+\mu}$. 
For equation (9), interest rate can affect housing price through demand, $\frac{\beta}{\alpha+\mu} \cdot \ln \left(\frac{(1+r)^{t}-1}{r(1+r)^{t}}\right)$, and supply $\frac{v}{\alpha+\mu} \cdot \ln r$. For demand, as $(1+r)^{t}>>11$, then:

$$
\ln \left(\frac{(1+r)^{t}-1}{r(1+r)^{t}}\right) \approx \ln \left(\frac{(1+r)^{t}}{r(1+r)^{t}}\right)=\ln \frac{1}{r}=-\ln r
$$

Equation (9) can then be modified as:

$$
\mathrm{p}=\mathrm{c}_{1}-\mathrm{c}_{2} \cdot \mathrm{b}+\left(\mathrm{c}_{3}-\mathrm{c}_{2}\right) \cdot \ln \mathrm{r}+\mathrm{c}_{4} \cdot \mathrm{e}+\mathrm{c}_{5} \cdot \mathrm{y} .
$$

Let $c_{3}^{\prime}=c_{3}-c_{2}$, then equation (11) can be rewritten as:

$$
\mathrm{p}=\mathrm{c}_{1}-\mathrm{c}_{2} \cdot \mathrm{b}+\mathrm{c}_{3}^{\prime} \cdot \ln \mathrm{r}+\mathrm{c}_{4} \cdot \mathrm{e}+\mathrm{c}_{5} \cdot \mathrm{y}+\mathrm{c}_{6} \cdot \mathrm{m}
$$

As Chinese government change its policy frequently, we suppose buyers can not have a rational long term expectation of housing prices, then:

$$
\mathrm{e}=\ln (\mathrm{P})-\ln (\mathrm{P}(-4)=\mathrm{p}-\mathrm{p}(-4) \text {. }
$$

Among which: $\mathrm{p}(-4)$ stands for logarithmic housing prices with 4 quarters lag.

\section{Empirical Analysis}

\section{Multicollinearity test}

Table 1 Parameter Estimates ${ }^{2}$

\begin{tabular}{|l|l|r|r|r|r|r|r|}
\hline Variable & Label & $\mathrm{DF}$ & $\begin{array}{r}\text { Parameter } \\
\text { Estimate }\end{array}$ & $\begin{array}{r}\text { Standard } \\
\text { Error }\end{array}$ & $\mathrm{t}$ Value & $\operatorname{Pr}>|\mathrm{t}|$ & $\begin{array}{r}\text { Variance } \\
\text { Inflation }\end{array}$ \\
\hline Intercept & Intercept & 1 & 1.74502 & 0.25308 & 6.90 & $<.000$ & 0 \\
& & 1 & 0.08989 & 0.05600 & 1.61 & 0.1170 & 1119.6947 \\
\hline Bank loan & $\mathrm{b}$ & 1 & -0.00750 & 0.02234 & -0.34 & 0.7390 & 3.12528 \\
\hline Interest rate & $\mathrm{lnr}$ & 1 & 0.37704 & 0.07350 & 5.13 & $<.000$ & 3.63364 \\
\hline expectation & $\mathrm{e}$ & 1 & -0.01892 & 0.07711 & -0.25 & 0.8075 & 1372.5651 \\
\hline $\begin{array}{l}\text { Money } \\
\text { supply }\end{array}$ & $\mathrm{m}$ & 1 & 0.21669 & 0.02226 & 9.74 & $<.000$ & 113.24031 \\
\hline GDP & $\mathrm{y}$ & & & & & 1 & 3 \\
\hline
\end{tabular}

${ }^{1}$ Conservatively estimated, if mortgage interest rate is $5 \%$, loan period is 120 months, then $(1+r){ }^{t}>120$.

${ }^{2}$ Table 1 and 2 is calculated by SAS9.1. 
$\mathrm{R} 2=0.9983$, adjusted $\mathrm{R} 2=0.9981, \mathrm{~F}=4316.05, \mathrm{P}<0.0001$

The sample period spans over 2000Q1 to 2013Q3, the data are collected from the website of National Statistic Bureau, China Central Bank, and China Macro Statistics Database. Due to its seasonality, GDP was adjusted by ARIMA $-\mathrm{X}-12$ method.

If the independent variables are highly related, then OLS regression may result in a higher variance, which may cause the equation unstable, or even contrast with the economic meaning. VIF is the most used statistic index to diagnose co linearity, when VIF> 10 , it is considered to have serious co linearity. The result of model (12) is shown in table 1, among which, VIF of 3 variables are greater than 10, hence the model has great co linearity problem.

\section{Principal component analysis}

Through principal analysis, the variables with co linearity are decomposed with a few uncorrelated variables, which are called principal components, then regress dependent variable with the principals, and then deducted back to the original variables regression. This method was accepted by more and more researchers.

We use principal component method to do the regression of equation (12), choose the former 3 variables, find that the RMSE increased from 0.0072 to 0.0094 , and the variance inflations are all less than 1.03 . The co linearity problem was avoided.

Tabel 2 principal components regression

\begin{tabular}{|l|c|c|c|c|c|r|r|r|r|}
\hline obs & TYPE & PCOMIT & RMSE & Intercept & $\begin{array}{c}\text { Bank } \\
\text { loan }\end{array}$ & $\begin{array}{c}\text { Interest } \\
\text { rate }\end{array}$ & expextation & $\begin{array}{c}\text { Money } \\
\text { supply }\end{array}$ & GDP \\
\hline 1 & PARMS & $\cdot$ & 0.0072 & 1.7450 & 0.0899 & -0.0075 & 0.3770 & -0.0189 & 0.2167 \\
\hline 2 & IPCVIF & 3 & & & 0.1741 & 1.2076 & 1.0184 & 0.1532 & 0.1084 \\
\hline 3 & IPC & 3 & 0.0094 & 1.4221 & 0.0831 & 0.0762 & 0.4584 & 0.1010 & 0.0986 \\
\hline
\end{tabular}

Table 2 also shows that housing price expectation plays the most important role in housing prices, its elasticity is 0.46 . The elasticity of mortgage loan and money supply is between 0.08 and 0.099 . It is worth noting that macro control policy has very week influence, its symbol is negative, which means the macro controlling policy is invalid.

\section{Conclusion}

Though the above analysis, we can see that China's housing price was mainly supported by expectation, the second important factor is GDP, which has an elasticity of 0.1 , while the elasticity of bank mortgage loan and money supply are between 0.08 and 0.099 . And the macro control policies hardly play any role in controlling housing prices. In order to control the increasing speed of China's housing prices, the most important thing is to change the residents' expectations, and then accompanied by monetary policies such as bank loan control and interest rate changes.

\section{Acknowledgement}

This research was financially supported by Guangdong Province Social Science Foundation. Item number GD10JYY04.

\section{References}

[1] C.M. Xu, Credit policy and housing price bubble. Chinese journal of Industry Economy Study,18(2005):43-50.

[2] J.K. Zhou, Effect of interest rate and exchange rate change on housing prices, Chinese Journal of Finance Theory and Practice. 329(2006):3-6. 
[3] K. McQuinn., G.O. Reilly, A model of cross-country house prices, Central Bank of Ireland working paper 2007.

[4] A. Katrin, S.Gerlach, Monetary policy, asset prices and macroeconomic conditions: a panel-VAR stury, Swiss National Bank working paper 2008, 1-30.

[5] W.C. Wheaton, G. Nechayev, The 1998-2005 "bubble" and the current "correction": what's different this time? Journal of Real Estate Review 30 (2008):1-26.

[6] K. Adam., P. Kuang., A. Marcet, House price booms and current account, London School of Economics Working paper 2011.

[7] X.Q. Ping, M.Y. Chen, Financing, land prices and housing price trend, Chinese journal of World Economy, 2004(7):3-11.

[8] J.K. Zhou, Monetary policy, bank lending and housing prices: a case of 4 municipalities, Chinese journal of Finance and Trade Economy, 2005(5):22-27.

[9] T. Zhang, L.T. Gong, Y.X. Pu, Asset return, housing mortgage loan, and equilibrium housing prices, Chinese journal of financial study, 308 (2006), 1-11.

[10] S . Gerlach, W.S. Peng, Bank Lending and Property Prices in Hong Kong, Journal of Banking and Finance, 29 (2005):461-481.

[11] J.F. Li, C.Y. Shi, The effect of bank credit on housing price fluctuations, Chinese Journal of Shanghai Finance and Economy University, 2005(2):26-32.

[12] J. Li, and Y. Deng, Study on the monetary factors to push housing prices-a comparison between U.S., Japan and China, Chinese Journal of Financial Study, 372 (2011):18-32.

[13] G. Yang, H.W.Wang, Y.K. Xie, Monetary policy instruments and housing prices: a compare analysis of macro controlling effects, Chinese Journal of Modern Finance and Economics, 268(2012):27-34. 